\title{
Development of Sweet Melon (Cucumis melo) Genotypes Combining High Sucrose and Organic Acid Content
}

\author{
Yosef Burger, Uzi Sa'ar, Asaph Distelfeld, and Nurit Katzir \\ Department of Vegetable Crops, Agricultural Research Organization, Newe Ya'ar Research Center, P.O. \\ Box 1021, Ramat Yishay 30095, Israel \\ Yelena Yeselson, Shmuel Shen, and Arthur A. Schaffer ${ }^{1}$ \\ Department of Vegetable Crops, Agricultural Research Organization, Volcani Center, P.O. Box 6, Bet \\ Dagan 50250, Israel
}

\begin{abstract}
AdDITIONAL INDEX WORDs. fruit quality, citric acid, malic acid, pH, sugars
ABstract. The sweet cultivars of Cucumis melo are characterized by high sucrose levels, together with low acid levels in the mature fruit flesh. The trait of high sugar accumulation in $C$. melo fruit is determined by a single recessive gene, suc. High acid content, conferred by a single dominant gene, $S o$, is found only in $C$. melo varieties that do not accumulate high levels of sugar and are used for nondessert purposes. We combined the genetic traits of high acid content (low $\mathrm{pH}$ ) and high sugar levels by crossing the nonsweet, high acid $\mathrm{C}$. melo var. flexuosus, 'Faqqous' (So/So, Suc/Suc), with high sugar, low acid C. melo genotypes (so/so, suc/suc) and generating the recombinant genotype So/-, suc/suc. Segregating $\mathrm{F}_{2}$ populations derived from the cross between 'Faqqous' and a standard high sugar, low acid line showed that the traits of high sugar and low $\mathrm{pH}$ were inherited independently of each other. The accumulation of acid and sugar in the developing fruit of a recombinant high acid, high sugar breeding line, A6, were also temporally independent, with acid accumulation preceding the rise in sucrose levels. The low $\mathrm{pH}$ of $\mathrm{A} 6$ was correlated with the developmental increase in titratable acidity and particularly of citric acid levels. The combination of increased acidity and high sugar provides the melons with a unique taste due to a sugar to acid ratio not present in sweet $C$. melo cultivars. These results are discussed in terms of the evolution under domestication of $C$. melo.
\end{abstract}

Sensory quality of fruit is largely determined by its sugar and organic acid levels (Sweeney et al., 1970), in addition to the volatile aromatic components. The sweet melon varieties (Cucumis melo L.) of the reticulatus, inodorus and cantaloupensis groups are unique in that organic acid levels play little role in determining their quality, which is determined primarily by sweetness alone (Yamaguchi et al., 1977). This is in contrast to practically all other fruit in which fruit acidity, and especially the sugar/acid ratio, are indicators of fruit quality.

Sweet melons have a low organic acid content. Citric acid is the major organic acid in the sweet melon cultivars studied, with levels of about only $0.2 \%$ fresh weight; malic acid levels are even lower (Leach et al., 1989; Lindner et al., 1963; Sweeney et al., 1970; Wang et al., 1996). Watermelons also have a low acid content but malic acid serves as the major organic acid in the mature fruit (Chisholm and Picha, 1986; Pratt, 1970). This is in contrast to other ripe fruit such as strawberry ( $0.6 \%$ to $1.1 \%$ citric), pineapple (1.4\% citric), or apricot $(0.8 \%$ malic), all of which have acidic fruit $\mathrm{pHs}$ in the mature fruit (Ulrich, 1970).

However, variation in acid content of mature fruit does exist in Cucumis. For example, the mature cucumber accumulates high levels of citric acid (1.4\%) during the later stages of fruit development, after the immature stage at which they are generally consumed (McFeeters et al., 1982). Although sweet melon cultivars have low acid levels, other $C$. melo groups have fruit with high acidity in the

Received for publication 26 Nov. 2002. Accepted for publication 19 Mar. 2003 This research project was funded in part by grants from the Chief Scientist Fund and the Director's Fund of the Israel Ministry of Agriculture and from the Ministry of Science. The authors wish to thank Harry Paris and Marina Petreikov for fruitful comments and assistance. The paper is contribution 144/2002 from the Institute of Field and Garden Crops, Agricultural Research Organization, Bet Dagan, Israel. 1To whom reprint requests should be addressed; e-mail vcaris@volcani.agri.gov.il. mature fruit (Kubicki, 1962; Mallick and Masui, 1986; Pitrat et al., 2000; Stepansky et al., 1999). These are often consumed when young, similar to a cucumber, before acids accumulate. However, these high acid genotypes do not accumulate the high levels of sugar characteristic of the sweet melon groups and the combination of high sugar and high acid does not appear to occur in the $C$. melo species. In a survey of 56 genotypes of $C$. melo, representing the broad genetic variability in both subspecies agrestis and subspecies melo, the combination of the traits of high sugar and low $\mathrm{pH}$ was conspicuously absent (Stepansky et al., 1999).

The trait of high sugar accumulation in C. melo fruit is determined by a single recessive gene, suc (Burger et al., 2002). Similarly, high acidity in $C$. melo fruit is also controlled by a single gene, So (Kubicki, 1962; Pitrat, 1998). Cultigens having high acidity and high sweetness of the fruit, a combination which theoretically should be conferred by the So/- suc/suc genotype, have not been described. Conceivably, the absence of high acid, high sucrose melons could result from an epistatic interaction between So and suc perhaps due to competition between the sugar accumulation and the organic acid accumulation metabolic pathways.

Our objective was to explore the possibility of combining high sugar and high acid levels in melon mesocarp in order to develop heretofore unknown melon types. In this paper we report the development and characterization of a breeding line combining the traits of high sugar and high acid levels in C. melo. These results are discussed in terms of the evolution under domestication of the species.

\section{Materials and Methods}

Plant material. Accessions of $C$. melo differing in sugar and acid levels were used in this study. The 'Faqqous' line (subsp. melo 
var. flexuosus) is a low sugar, high acid line which we previously used for a study of the inheritance of sugar accumulation (Burger et al., 2002). The 'Krymka', C8 and F63 lines are all low acid and high sugar breeding lines of the Galia type (subsp. melo var. reticulatus). The A6 high acid, high sugar line was developed from the cross between 'Faqqous' and 'Krymka', followed by a backcross to the 'Krymka' parent and the selection to the $\mathrm{F}_{8}$ generation. The 'Noy Yizre'el' breeding line is a sweet, low acid genotype of the Ha'Ogen type (subsp. melo var. cantalupensis) (Goldman, 2002; Pitrat et al., 2000).

Segregating $\mathrm{F}_{2}$ populations were developed from the cross of A6 and F63 as well as from the cross of the 'Faqqous' parent and 'Noy Yizre'el'. The $F_{2}$ populations were grown in the open field according to standard cultivation techniques and mature fruit were harvested at the half-slip stage. The $\mathrm{F}_{2}$ of 'Faqqous' and 'Noy Yizre'el' was used for the study of sucrose accumulation reported recently (population II, Burger et al., 2002). For the study of acid accumulation during fruit development the A6 and $\mathrm{C} 8$ breeding lines were grown in a greenhouse and trained to a single fruit per plant. Flowers were pollinated and tagged at anthesis and developing fruit were sampled throughout development.

MEASUREMENT OF TSS, PH, TITRATABLE ACIDITY, CITRIC AND MALIC ACID. About 50 grams of ripe fruit flesh, taken from the equatorial portion of the fruit after the rind and seed cavity were removed, were squeezed by hand and juice was collected and centrifuged to remove solid matter. Total soluble solids was measured by a digital refractometer (Atago, Japan). pH was measured using a standard digital $\mathrm{pH}$ meter (Hanna, Italy). Titratable acidity was measured by titration of a juice sample with $0.05 \mathrm{~N} \mathrm{NaOH}$, using phenophtalein as indicator. Citric and malic acids were assayed on the extracted juice using enzyme linked assay kits (Boehringer, Mannheim, Germany).

\section{Results}

An $\mathrm{F}_{2}$ segregating population was generated from the cross of the high acid, low sugar 'Faqqous' (So/So Suc/Suc) and the high sugar, low acid 'Noy Yizre'el' (so/so suc/suc) genotype, and used to study the inheritance of the two traits. The trait of acidity segregated as a single dominant gene $(\mathrm{So} /--$, high acid, $4.4<\mathrm{pH}<5.3$, $\mathrm{n}=192 ;$ so/so, low acid, $5.3>\mathrm{pH}>6.3, \mathrm{n}=67 ; \chi^{2}=0.11, \mathrm{df}=1$, $P=0.73$ for $3: 1$ ). The $\mathrm{F}_{1}$ and $\mathrm{BC}$ populations to each parent also

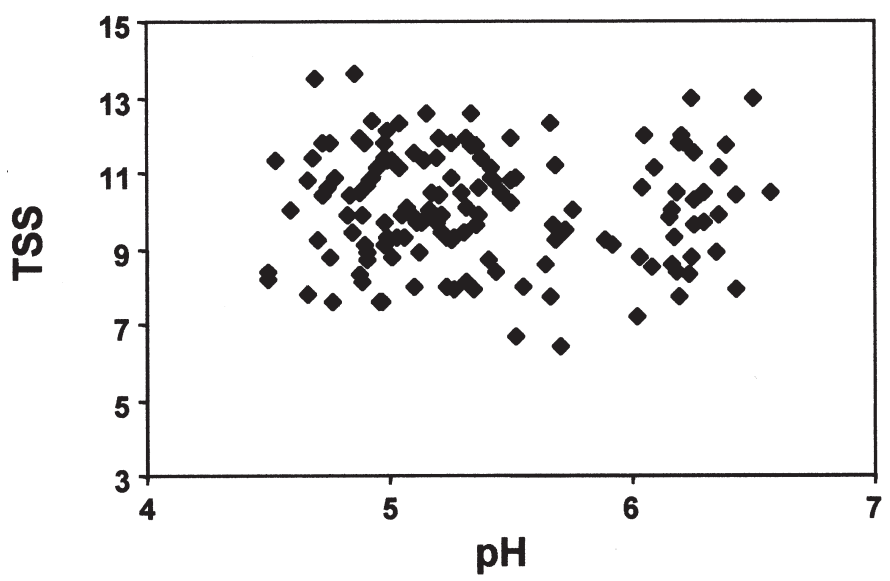

Fig. 1. Scatter plot of the Brix and $\mathrm{pH}$ values of extracted juice of individual mature fruit of a segregating $\mathrm{F}_{2}$ population derived from the cross of the high-acid sweet melon breeding line A6 and a standard low-acid sweet melon breeding line F63. segregated as expected for a single dominant gene (not presented). When combined with the results of sucrose levels for each of the individual fruit in this population (Burger et al., 2002) the data show that the two traits segregated independently, yielding a 9: 3:3:1 ratio of 151:45:43:16 (low pH, high sucrose, So/-- Suc/-- : low $\mathrm{pH}$, low sucrose, $S o /--$ suc/suc : high $\mathrm{pH}$, low sucrose, so/so Suc/-- : high $\mathrm{pH}$, high sucrose, so/so suc/suc) with a $\chi^{2}=1.21$, df $=3, P=0.75$.

The sweet, high acid breeding line A6 was developed from a cross between the high sugar, low acid 'Krymka' (var. reticulatus, so/so suc/suc) and the high acid, low sugar 'Faqqous'. The selection procedure throughout the breeding program was for both high TSS and low $\mathrm{pH}$ and the A6 breeding line combines both traits. To further show that the two traits are compatible we measured the Brix and $\mathrm{pH}$ values in mature fruit of 200 plants from a segregating $\mathrm{F}_{2}$ population from the cross between $\mathrm{A} 6$ and the low acid, high sugar line, F63. Figure 1 shows that there is no negative association between $\mathrm{pH}$ and TSS in the progeny derived from the cross of which both parents are high sucrose lines.

Table 1 shows the $\mathrm{pH}$ and organic acid levels of the mature fruit flesh of the high acid 'Faqqous', the high sugar, low acid line F63 and the A6 high sugar, high acid breeding line. The total organic acid levels of the three lines reflect the differences in $\mathrm{pH}$, with the two acidic lines containing in the range of about $3 \mathrm{mg} / \mathrm{g}$ fresh weight higher organic acid levels than the low acid F63 line. The addition of $\approx 3 \mathrm{mg}$ of either citric or malic free acid per $\mathrm{mL}$ of the low-acid melon juice can account for the decrease in $\mathrm{pH}$ (not presented). Interestingly, the composition of organic acids is different between the two high acid lines. The predominant organic acid in the 'Faqqous' line is malic acid while that of both the low acid F63 and the high acid A6 is citric.

The low $\mathrm{pH}$ in the high acid A6 line is due to the developmental decrease in $\mathrm{pH}$ which, in this experiment, began when the fruit was $\approx 20 \mathrm{~d}$ after anthesis (DAA), compared to a standard low acid line (Galia-C8 hybrid) in which $\mathrm{pH}$ values remained relatively unchanged throughout development (Fig. 2a). The acid line $\mathrm{pH}$ values continue to decrease to below 5.0 by 30 DAA and afterward remain stable. The developmental changes in $\mathrm{pH}$ are reflected in the developmental changes in titratable acidity (Fig. 2b). Until 20 DAA titratable acidity is similar in the two lines but by 30DAA the titratable acidity of the A6 line increased dramatically, parallel with the changes in $\mathrm{pH}$.

The $\mathrm{pH}$ and titratable acidity differences are reflected in the developmental changes in organic acid levels. The major difference in organic acid levels is accounted for by the increase in citric acid during this period (Fig. 3A). The A6 line also showed an increase in malic acid at 20 DAA but afterward malic acid levels decrease to low levels (Fig. 3B) and the major organic acid in the mature fruit of the both the high acid A6 and the low acid Galia-C8 is citric acid. Total organic acids in the A6 line accumulate to levels

Table 1. Average $\mathrm{pH}$ and organic acid levels in mature fruit of $C$. melo genotypes 'Faqqous' and breeding lines A6 and F63.

\begin{tabular}{lcccc}
\hline & & \multicolumn{3}{c}{ Acid content $\left(\mathrm{mg} \cdot \mathrm{g}^{-1}\right.$ fresh wt) } \\
\cline { 3 - 5 } Line & $\mathrm{pH}$ & Citric & Malic & Citric acid + \\
Faqqous & $4.92 \mathrm{~b}^{\mathrm{z}}$ & $1.28 \mathrm{~b}$ & $3.89 \mathrm{a}$ & $5.10 \mathrm{a}$ \\
A6 & $4.75 \mathrm{~b}$ & $3.91 \mathrm{a}$ & $0.89 \mathrm{~b}$ & $4.80 \mathrm{a}$ \\
F63 & $6.27 \mathrm{a}$ & $1.53 \mathrm{~b}$ & $0.28 \mathrm{c}$ & $1.80 \mathrm{~b}$
\end{tabular}

Letters within columns indicate statistical differences at $P=0.05$ (Student-Neuman-Keuls). Data are averages of individual measurements of 10 fruit of each genotype. 
$\approx 3 \mathrm{mg} \cdot \mathrm{g}^{-1}$ fresh weight higher than the Galia-C8 cultivar during the period between 20 and 30 DAA (Fig. 3C).

\section{Discussion}

We report here the recombinant $C$. melo genotype So/So suc/ suc which combines the genetic trait of high acidity with the high sugar levels characteristic of standard sweet melon dessert cultivars. Surprisingly, although the A6 line carries the trait of high acidity transferred from the 'Faqqous' genotype and controlled by a single major gene (Kubicki, 1962; Danin-Poleg et al., 2001), the control over the accumulation of the individual organic acids, whether malic or citric, is under independent genetic control (unpublished). Accordingly, the high acid 'Faqqous' parent is characterized by high malic levels while the high acid A6 has high citric levels.

The high sugar, high acid genotype combination does not appear to exist in any cultigen, as evidenced by the germplasm survey previously reported (Stepansky et al., 1999). In that study of 56 C. melo genotypes representing the broad spectrum of varieties in the species there were no examples of high acid together with high sucrose levels (>20 $\mathrm{mg} \cdot \mathrm{g}^{-1}$ fresh weight, Stepansky et al., 1999). In a further survey of germplasm (Burger, unpublished) we still have not found a sweet cultivar with high acid, although the three other combinations of acid and sugar (low sugar, low acid; low sugar, high acid; and high sugar, low acid) exist within the natural genetic variability for fruit quality in the species. The latter category of high sugar, low acid characterizes all commercial sweet melon cultivars.

Based on the absence of sweet and sour melons among the natural genetic variability of $C$. melo, it was logical to hypothesize that the traits of high sugar and high acid were incompatible. However,
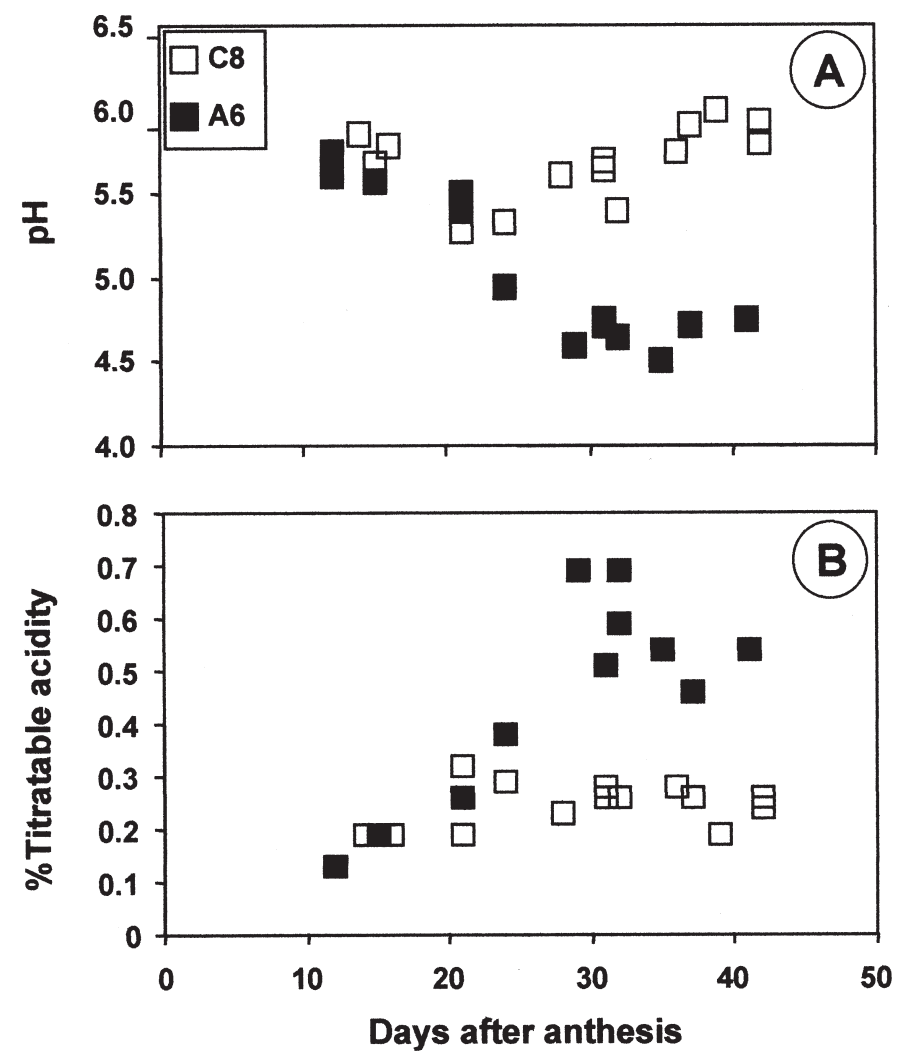

Fig. 2. Changes during fruit development of (A) $\mathrm{pH}$ and (B) titratable acidity of extracted juice of the high-acid, sweet melon breeding line A6 and a standard low-acid sweet melon hybrid Galia type genotype C8. our results clearly show that this is not the case. Our developmental studies show that the accumulation of acid and sucrose are temporally separated. Acid accumulation, which occured in this study $\approx 20$ to 30 DAA precedes sucrose accumulation, which only begins when acid accumulation is completed, at $\approx 30$ DAA (not shown), and which continues until abscission (Burger et al., 2000; Rosa, 1928; Schaffer et al., 1987, 1996). Furthermore, the absolute amounts of acid and sugar that account for the traits of high acid and high sugar are of a different magnitude. While a difference of only $3 \mathrm{mg} \cdot \mathrm{g}^{-1}$ fresh weight determines the acidity trait, 10 times that amount of sucrose characterizes the difference between the sweet and nonsweet genotypes (Burger et al., 2002).

This surprising observation may shed light on the evolution under domestication of the species. The traits of low acidity and high sugar are each recessive (so, Kubicki, 1962; suc, Burger et al., 2002) and we recently proposed that the evolution of horticultural sweet melon varieties required the sequential selection of three
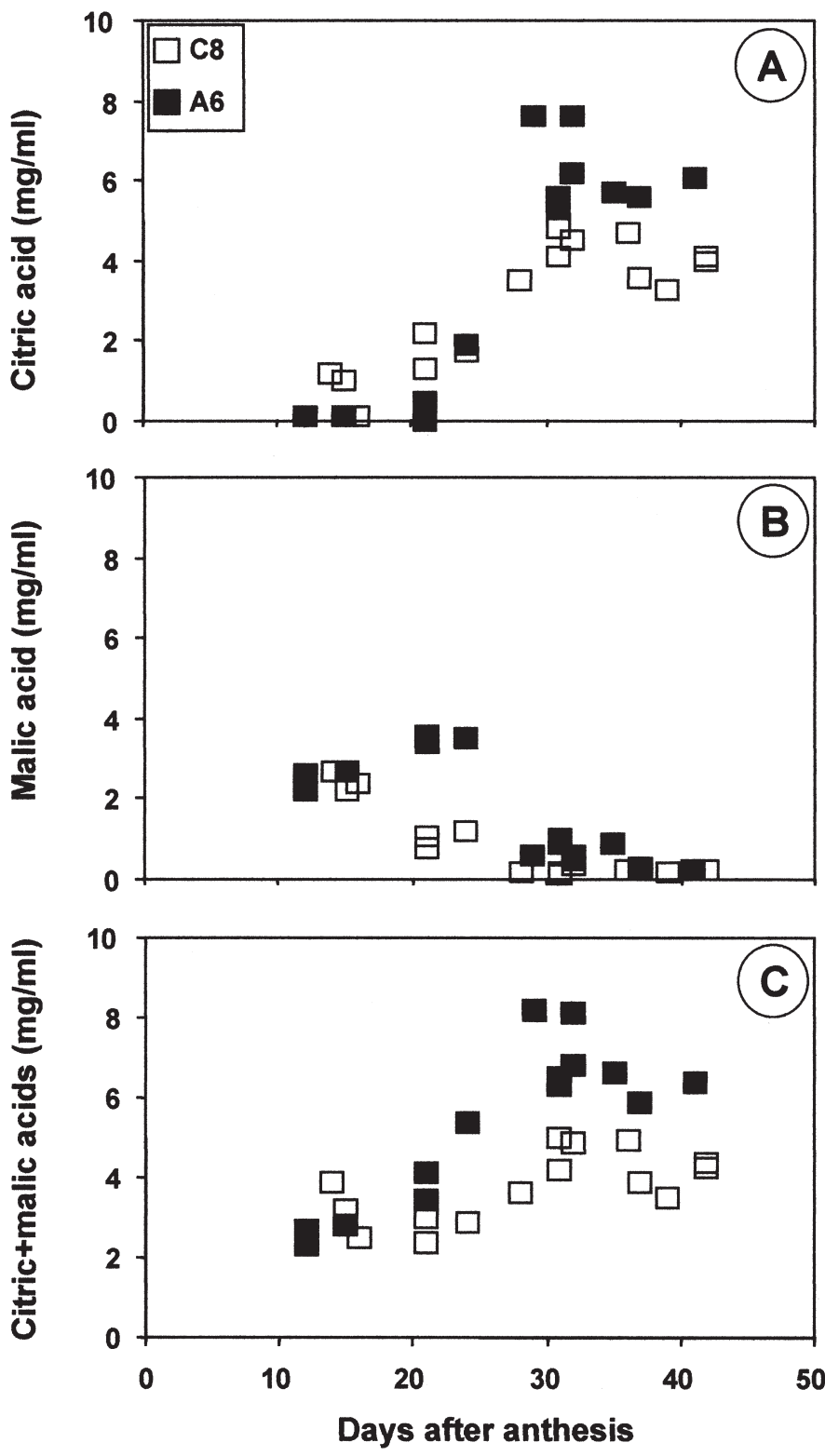

Fig. 3. Changes during fruit development of (A) citric acid, (B) malic acid, and (C) sum of citric and malic acids of extracted juice of the high-acid sweet melon breeding line A6 and a standard low-acid sweet melon hybrid Galia type genotype C8. 
recessive mutations: first a recessive mutation that allowed for nonbitter fruit (bif, Dewei et al., 1997), then a recessive mutation for low-acid fruit (so, Kubicki, 1962), followed by a recessive mutation for high sucrose fruit (Burger et al., 2002). The results of the present study, together with those of a previous study (Stepansky et al., 1999) indicate that selection for high sucrose accumulation characteristic of the dessert melons occured in the recessive nonsour (so) background and is limited to that background, and indicates that the so mutation preceded the development of high sucrose genotypes. Afterward, continued selection and horticultural breeding was limited to a relatively small gene pool consisting of sweet, nonsour melon types. Therefore, the horticultural dessert cultivars are based on, and limited to, a narrow gene pool. Accordingly, the pool may be significantly broadened by incorporating desirable traits from otherwise horticulturally poor, nonsweet, high acid genotypes in breeding programs. Such horticulturally inferior germplasm has served to contribute to the improvement of fruit quality (Schaffer et al., 1999; Tanksley and McCouch, 1997).

In sweet melons absence of adequate sugar leads to poor quality since sweetness alone is the overwhelming quality component (Yamaguchi et al., 1977). Practically all other fruit are characterized by higher acidity than that found in sweet melons and the balance between sugar and acid is a major determinant of fruit quality and taste. The combination of the two traits in melons opens up the possibility of breeding unique tasting melons with taste reflecting the sugar/acid ratio.

\section{Literature Cited}

Burger, Y., S. Shen, M. Petreikov, and A.A Schaffer. 2000. The contribution of sucrose to total sugar content in melons. In: N. Katzir and H.S Paris (eds.). Proc. Cucurbitaceae 2000. Acta Hort. 510:479-485.

Burger, Y., U. Saar, N. Katzir, H.S. Paris, Y. Yeselson, I. Levin, and A.A. Schaffer. 2002. A single recessive gene for sucrose accumulation in Cucumis melo fruit. J. Amer. Soc. Hort. Sci. 127:938-943.

Chisholm, D.N. and D.H. Picha. 1986. Distribution of sugars and organic acids in ripe watermelon fruit. HortScience 21:501-503.

Danin-Poleg, Y., N. Reis, G. Tzuri, and N. Katzir. 2001. Development and characterization of microsatellite markers in Cucumis. Theor. Appl Genet. 102:61-72.

Dewei, M., S. Lan, L. Y. Hui, Z. Yanping, and L. Haihe. 1997. A genetic model of bitter taste in young fruit of melon. Cucurbit Genet. Coop. Rpt. 20:27-29.

Goldman, A. 2002. Melons for the passionate grower. Artisan, New York.

Kubicki,B. 1962. Inheritance of some characters in muskmelons (Cucumi melo L.). Genet. Polonica 3:265-274.

Leach, D.N., V. Sarafis, R. Spooner-Hart, and S.G. Wyllie. 1989. Chemical and biological parameters of some cultivars of Cucumis melo. Acta Hort. 247:353-357.

Lindner, K., S. Hapka, M. Kramer, and K. Szoke. 1963. Diatetische bewertung verschiedener in ungran angebauterzucker und wassermelonensorten. Qualitat. Pl. Mater. Veg. 9:203-216

Mallick, M.F.R. and M. Masui. 1986. Origin, distribution and taxonomy of melons. Scientia Hort. 28:251-261.

McFeeters, R.F., H.P. Fleming, and R.L. Thompson. 1982. Malic and citric acid in pickling cucumbers. J Food Sci 47:185-186.

Pitrat, M. 1998. 1998 Gene list for melon. Cucurbit Genet. Coop. Rpt. 21:69-81.

Pitrat, M., P. Hanelt, and K. Hammer. 2000. Some comments on infraspecific classification of cultivars of melon. In: N. Katzir and H.S. Paris (eds.). Proc. Cucurbitaceae 2000. Acta Hort. 510:29-36.

Pratt, H.K. 1970. Melons, p. 207-232. In: A.C. Hulme (ed.). The biochemistry of fruit and their products. vol. 2. Academic Press, New York.

Rosa, J.T. 1928. Change in composition during ripening and storage of melons. Hilgardia 3:421-443.

Schaffer, A.A., B. Aloni, and E. Fogelman. 1987. Sucrose metabolism and accumulation in developing fruit of Cucumis. Phytochemistry 26 : $1883-1887$.

Schaffer, A.A., D.M. Pharr, and M. Madore. 1996. Cucurbits, p. 729-758. In: E. Zamski and A.A. Schaffer (eds.) Photoassimilate partitioning in plants and crops:source-sink relationships. Marcel Dekker, New York.

Schaffer A., M. Petreikov, D. Miron, M. Fogelman, M. Spiegelman, Z. Bnei-Moshe, S. Shen, D. Granot, R. Hadas, N. Dai, I. Levine, M. Bar, M. Friedman, M. Pilowsky, N. Gilboa, and L. Chen. 1999. Modification of carbohydrate content in developing tomato fruit. HortScience 34:12-15.

Stepansky, A. I. Kovalski, A. Schaffer, and R. Perl-Treves. 1999. Variation in sugar levels and invertase activity in mature representing a broad spectrum of Cucumis melo genotypes. Genet. Res. Crop Evolut. 46:53-62.

Sweeney, J.P., V.J. Chapman, and P.A. Hepner. 1970. Sugar, acids and flavor in fresh fruit. J. Amer. Diet. Assn. 57:432-435.

Tanksley, S.D. and S.R. McCouch. 1997. Seed banks and molecular maps: unlocking genetic potential from the wild. Science 277:1063-1066

Ulrich, R. 1970. Organic acids, p. 89-118. In: A.C. Hulme (ed.). The biochemistry of fruit and their products. vol. 1. Academic Press, New York.

Wang, Y, S., G. Wyllie, and D.N. Leach. 1996. Chemical changes during the development and ripening of the fruit of Cucumis melo (cv. Makdimon). J. Agr. Food Chem. 44:210-216

Yamaguchi, M., D.L. Hughes, K. Yabumoto, and W.C. Jennings. 1977. Quality of cantaloupes: variability and attributes. Scientia Hort. 6 : 59-70. 